\title{
Determining the Optimal and Ideal Helmet for an Italian Scooter Used in a Smart City Considering Cranial Anthropometry and Intelligent Data Analysis
}

\author{
Mariana Martinez-Valencia ${ }^{1}$, José-Antonio Vazquez-Lopez ${ }^{1}$, \\ Carolina Hernandez-Navarro ${ }^{2}$, Alberto Ochoa ${ }^{3}$, Juan-Luis Hernandez-Arellano ${ }^{3}$ \\ ${ }^{1}$ Instituto Tecnológico Nacional de México en Celaya, Departamento de Ingeniería Industrial, \\ Celaya, Guanajuato., Mexico \\ 2 Instituto Tecnológico Nacional de México en Celaya, Departamento de Ingeniería Mecánica, \\ Celaya, Guanajuato., Mexico \\ 3 Universidad Autónoma de Ciudad Juárez, Laboratorio de Diseño Ergonómico de Producto, \\ Ciudad Juárez, Chihuahua, Mexico \\ luis.hernandez@uacj.mx
}

\begin{abstract}
The main objective of the present research was to develop an intelligent data analysis from anthropometric data to find tendencies and patrons before stating the design of an optimal and ideal helmet to be used in an Italian scooter. Using a database of the anthropometric properties of the craniofacial structures of a sample of students in a border society. A set of 14 craniofacial dimensions were obtained using 13 reference anthropometric points (Glabella, Vertex, Opisthocranion, Eurion, Alare, Gnathion, Nasion, Nasoespinhale, Frontotemporale, Porion, Exocanthion, Endocantion, and Zygion). We used a ROSSCRAFT anthropometer model CAMPBELL 10 RC10, a ROSSCRAFT metallic tape, and an ErgoTechMx brand ErgoMeasure model anthropometer. 130 students, 69 men, and 61 women enrolled in said University were measured. The values of mean, standard deviation, maximum and minimum were calculated. Finally, we analyze the data obtained to determine the ideal thickness of the helmet and how it can help reduce deaths in road accidents.
\end{abstract}

Keywords: anthropometry, intelligent data analysis, product design.

\section{Introduction}

\subsection{Background}

An Italian scooter is a type of motorized two-wheeled vehicle, with an open frame in which the driver sits without straddling any part of the engine. Most modern scooters have smaller wheels than motorcycles, between 12 and 15 inches $(30-37.5 \mathrm{~cm})$ in diameter and were ideally created for urban use and are currently being promoted for mass use in a Smart City, as is shown in Figure 1. 


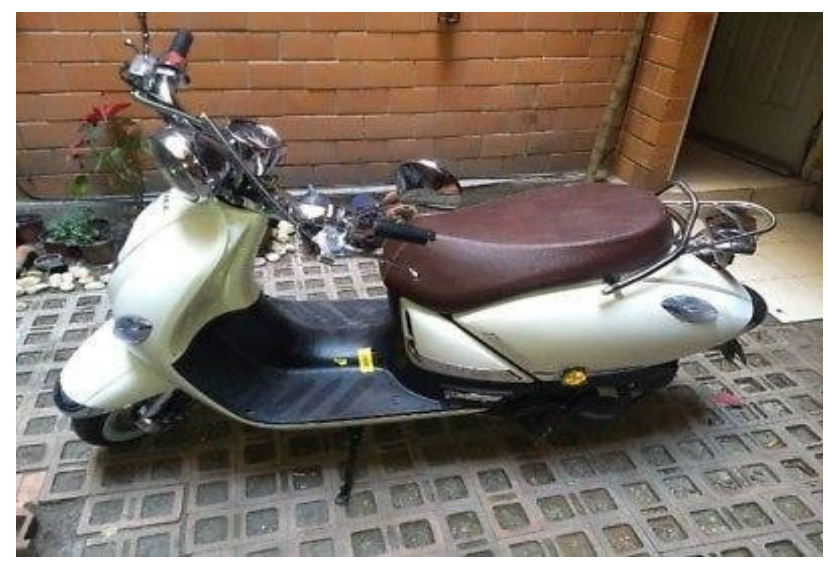

Fig. 1. An Italian Scooter used in diverse societies.

In terms of its design and mechanics, in contrast to most of the motorcycles, scooters tend to have a carriage, including a frontal protection for the legs and a body that hides all or most of the mechanics. The classic design of the scooter has a flat floor for the driver's feet and often includes some integrated storage space, either under the seat, in the front leg protection or both.

Most old scooters and some recent retro models have a manual transmission with the shift lever and the clutch on the left handlebar. The motor of the scooter is usually under the seat with a continuous variable transmission transferring the power to the rear wheel, often in a front axle arrangement that allows the rear of the engine to oscillate vertically in conjunction with the movement of the rear wheel.

Until relatively recently, most modern scooters had air- cooled two-stroke engines with fuel and air blends by carburizing, although some high-end ones are water-cooled, such as the Honda FC50 or the Yamaha YG50 of 2002. Most scooters have smaller engines than motorcycles (between $30 \mathrm{ccs}$ and $250 \mathrm{ccs}$ with a single cylinder). Those of $49 \mathrm{ccs}$ or less displacement are classified in most countries as a moped and are subject to safety restrictions and reduced rates. Since the 90s are increasingly common four-stroke engines that allow compliance with the strictest emission controls, the mixture of fuel and air by injection and models with larger displacement: $300 \mathrm{cc}, 400 \mathrm{cc}, 500 \mathrm{cc}$ and up to $800 \mathrm{cc}$ that are usually called maxiscooters. Significant examples of these models are the Kymco SuperDink 300, Yamaha T-Max, SYM Joymax 300i or the Piaggio X9. Recently, they are also appearing in the market and they begin to popularize the scooters of three wheels to which we should consider tricycles and not bicycles like the Piaggio MP3 or the Yamaha Tricity 125.

\subsection{Anthropometry}

Anthropometry is a simple and reliable method to quantify the size and proportions of the body by measuring the length, width, circumference, and thickness of the skin fold of the body [1], [2]. Updated anthropometric data are very important for any population/civilization since the determination of the correct dimensions of objects 
depends to a large extent on the improvement of existing anthropometric data [3]. Anthropometry practices aim, through the correct use of the conventional anthropometer, to identify, correctly measure the body segments of the human being, perform the appropriate statistical calculation to integrate the data acquired in an anthropometric chart and correctly apply the measurements in the design of products, objects, spaces and work stations, among other applications [4].

Craniofacial anthropometry has become an important tool used by both clinical geneticists and reconstructive surgeons [5]. The study of the craniofacial anthropometric characteristics is of fundamental importance to solve problems related to the identification and quantification of syndromic clinical characteristics, the planning of treatments and reconstructive surgeries, the control of the operative results and the evaluation of the longitudinal change of the skull.

The craniometric analysis is done by locating the anthropometric points and determining the anthropometric measurements, which have already been established in the literature, these can usually be obtained by simple rules, calibers and other specific tools [6].

\subsection{Data Mining}

Data Mining is the extraction of hiding and predictable information inside great data bases, also, is a powerful new technology with great potential to help to the companies or organizations to focus on the most important information in their Bases of Information (Data Warehouse). Data Mining tools predict future tendencies and behaviors, allowing businesses to make proactive decisions leaded by knowledgedriven information. The automated prospective analyses offered by a product thus go beyond past events provided by retrospective typical tools of decision support systems. Data Mining tools can respond to questions of businesses that traditionally consume too much time to be solved and to which the users of this information almost are not willing to accept. These tools explore the data bases searching for hidden patterns, finding predictable information that sometimes an expert cannot find because this is outside expectations as is shown in Figure 3.

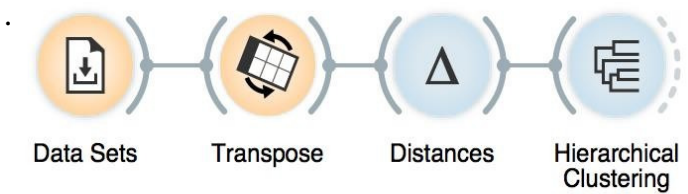

Fig. 3. Intelligent Data Analysis.

The motivation to make an approach by means of applications with Data Mining is based on previous works of Social Data Mining in this research area. This research area emphasizes the role of the collective analysis of conduct effort, rather that the individual one. A social tendency results from the decisions of many individuals joined only in the location in where they choose to coexist, yet this, still it reflects a rough notion of what the researchers of the area find of what could be a correct and 
valid social tendency. The social tendency reflects the history of the use of a collective behavior and serves as a base to characterize the behavior of future descendants. The Data Mining approaches for social aspects look for analogous situations in the behavior registers. The investigators look for situations where the groups of people are producing computer registers (such as documents, USENET messages, or Web sites and links to groups with a specific profile) like part of its normal activity. The potentially useful information implicit in these files is identified and the computer techniques to display the results are designed. Thus, the computer discovers and makes explicit the "social tendencies through the time" created by a particular type of community.

\subsection{Objectives}

Once the background has been stablished, the main objectives of this study are to determine anthropometrics reference points and to develop and intelligent data analysis, both will be used in the design of an ergonomic helmet for an Italian scooter.

\section{Methodology}

\subsection{Study Design}

A transversal, descriptive and correlational study is present. A team of 3 anthropometrists was trained to perform craniofacial anthropometric measurements. The measurements were made in the Product Ergonomic Design Laboratory of the UACJ. The ethics committee of the Autonomous University of Ciudad Juarez, Mexico, reviewed and approved the study. The participants signed a consent form accepting their participation in the study, as well as the absence of health risks when participating in the study. The information collected was treated confidentially and was used only for academic purposes.

\subsection{Sample}

A convenience sample consisted of 130 students of the UACJ participated in the study. The age was between 18 and 30 years. The inclusion criteria were that the participants were free of physical injuries, without craniofacial fractures, deformities, or having undergone surgeries in the skull. The exclusion criteria included facial fractures, defects or posttraumatic deformities, congenital malformations, development of asymmetries, or the presence of implants.

\subsection{Materials}

An anthropometer brand ROSSCRAFT model CAMPBELL 10 RC-10, range $18 \mathrm{~cm}$, and a metal tape ROSSCRAFT mark, for anthropometric use range $200 \mathrm{~cm}$. The equipment has an accuracy of $0.5 \mathrm{~mm}$, is certified and calibrated by the manufacturer. 
ErgoMeasure vertical anthropometer range to $500 \mathrm{~cm}$ was used. The precision of the instrument is $\pm 1 \mathrm{~mm}$.

\subsection{Variables}

Fourteen dimensions of the head corresponding to distances between thirteen craniofacial anthropometric reference points (Glabella, Vertex, Opisthocranion, Eurion, Alare, Gnathion, Nasion, Nasoespinhale, Frontotemporale, Porion, Exocanthion, Endocantion, and Zygion) were measured, which are described in Table 1. Table 2 shows the names of the craniofacial anthropometric dimensions. Figure 2 shows the cranial and head dimensions used in the study.

Table 1. Anthropometric anatomical points.

\begin{tabular}{ccc}
\hline $\mathbf{N}^{\circ}$ & Name & Abbreviation \\
\hline \hline 1 & Eurion & $\mathrm{Eu}$ \\
2 & Vertex & $\mathrm{V}$ \\
3 & Opisthocranion & $\mathrm{Op} \mathrm{Ft}$ \\
4 & Frontotemporale & \\
5 & Porion & $\mathrm{Po}$ \\
6 & Gnathion & $\mathrm{Gn}$ \\
7 & Zygion & $\mathrm{Zy}$ \\
8 & Glabela & $\mathrm{G}$ \\
9 & Nasion & $\mathrm{N}$ \\
10 & Nasoespinhale & $\mathrm{Ns}$ \\
11 & Alare & $\mathrm{Al}$ \\
12 & Exocanthion & $\mathrm{Ex}$ \\
13 & Endocanthion & $\mathrm{It}$ \\
\hline
\end{tabular}

Table 2. Craniofacial anthropometric measurements.

\begin{tabular}{ccc}
\hline $\mathrm{N}^{\circ}$ & Anthropometric Dimension Reference & Anthropometric Points \\
\hline \hline 1 & Head Width & $\mathrm{Eu}-\mathrm{Eu}$ \\
2 & Skull length & $\mathrm{G}-\mathrm{Op}$ \\
3 & Nasal amplitude & $\mathrm{Al}-\mathrm{Al}$ \\
4 & Nasal height & $\mathrm{N}-\mathrm{Ns}$ \\
5 & Facial amplitude & $\mathrm{N}-\mathrm{Gn}$ \\
6 & Forehead width & $\mathrm{Ft}-\mathrm{Ft}$ \\
7 & External inter-chamber distance & $\mathrm{Ex}-\mathrm{Ex}$ \\
8 & Internal intercantal distance & $\mathrm{En}-\mathrm{En}$ \\
9 & Facial widht & $\mathrm{Zy}-\mathrm{Zy}$ \\
\hline
\end{tabular}


Mariana Martinez-Valencia, José-Antonio Vazquez-Lopez, Carolina Hernandez-Navarro, et al.

\begin{tabular}{ccc}
\hline $\mathrm{N}^{\circ}$ & Anthropometric Dimension Reference & Anthropometric Points \\
\hline \hline 10 & Head circumference & G-Op \\
11 & Length G-V-Op & G-V-Op \\
12 & Length Eu-V-Eu & Eu-V-Eu \\
13 & Length V-Gn & V-Gn \\
14 & Length V-Po & V-Po \\
15 & Head height & V-N \\
\hline
\end{tabular}

\subsection{Data Analysis}

Mean, maximum, minimum, and standard deviation were calculated for each item. The intelligent data analysis was developed using the Weka software, a program that contains multiple machine learning algorithms. Attributes that have less variation between instances to dismiss them from the analyzes were searched. A clustering was performed to group the data and find patterns in the data set.

\section{Results Using Intelligent Data Analysis}

\subsection{Descriptive Analysis}

Table 3 shows the mean, minimum, maximum and standard deviation of the collected data for men and women.

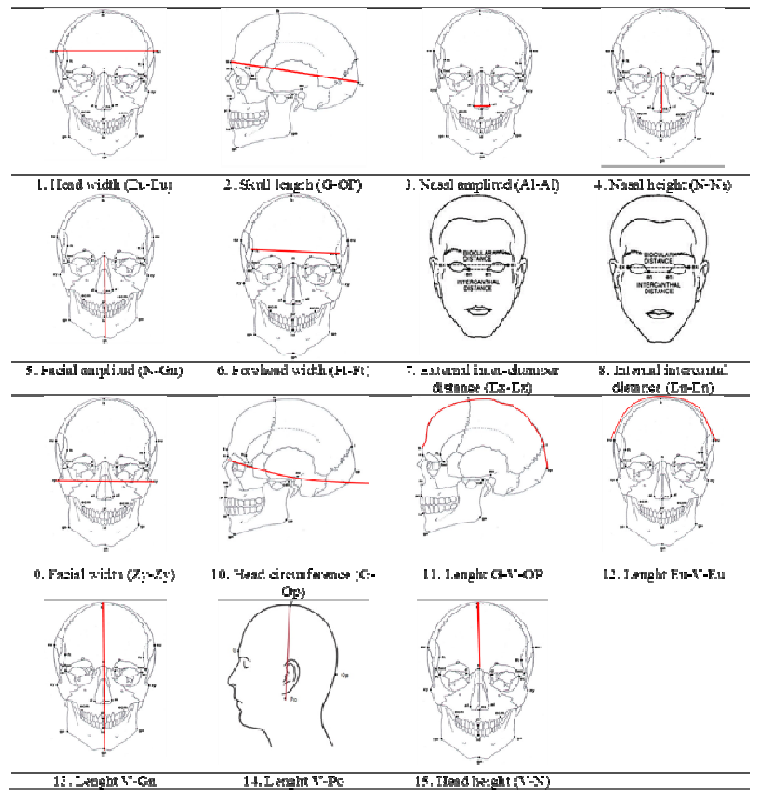

Fig. 2. Cranial and head dimensions used in the study. 


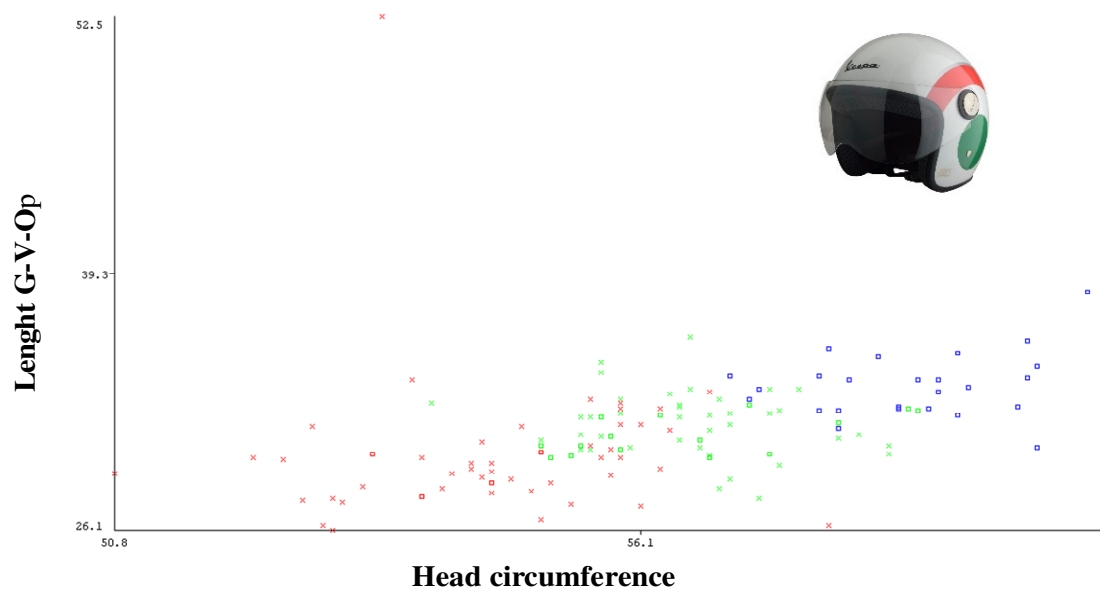

Fig. 3. Data Mining and Clustering Analysis.

Table 3. Descriptive statistics.

\begin{tabular}{lllllll}
\hline \multirow{2}{*}{$n$} & \multicolumn{3}{c}{ Men $(\mathrm{n}=69)$} & \multicolumn{2}{c}{ Women $(\mathrm{n}=61)$} \\
\cline { 2 - 7 } $\mathrm{Eu}-\mathrm{MIN}$ & 142 & 170 & $156.62 \pm 6.13$ & 139 & 166 & $150 \pm 5.65$ \\
\hline \hline $\mathrm{G}-\mathrm{Mp}$ & 174 & 219 & $194.70 \pm 9.05$ & 171 & 201 & $185.66 \pm 7.05$ \\
\hline \hline $\mathrm{Al}-\mathrm{Al}$ & 27 & 47 & $34.59 \pm 3.02$ & 26 & 36 & $31.97 \pm 2.28$ \\
\hline \hline $\mathrm{N}-\mathrm{Ns}$ & 43 & 59 & $51.96 \pm 3.34$ & 38 & 57 & $46.92 \pm 3.90$ \\
\hline $\mathrm{N}-\mathrm{Gn}$ & 103 & 140 & $124.04 \pm 6.93$ & 99 & 128 & $112.54 \pm 6.68$ \\
\hline \hline Ft-Ft & 75 & 125 & $105.35 \pm 9.46$ & 77 & 126 & $99.2 \pm 10.08$ \\
\hline \hline Ex-Ex & 95 & 115 & $104.41 \pm 4.34$ & 87 & 112 & $99.67 \pm 5.20$ \\
\hline \hline En-En & 26 & 36 & $31.25 \pm 2.55$ & 24 & 35 & $29.34 \pm 2.85$ \\
\hline \hline Zy-Zy & 130 & 158 & $142.84 \pm 6.85$ & 105 & 154 & $133.26 \pm 9.57$ \\
\hline \hline Perímeter G-Op & 534 & 614 & $573.52 \pm 17.07$ & 508 & 601 & $552.57 \pm 17.21$ \\
\hline \hline G-V-Op & 277 & 383 & $321.78 \pm 20.86$ & 261 & 525 & $303.74 \pm 34.70$ \\
\hline \hline Eu-V-Eu & 286 & 370 & $320.29 \pm 16.53$ & 263 & 338 & $301.64 \pm 18.01$ \\
\hline \hline V-Gn & 197 & 249 & $224.39 \pm 11.68$ & 185 & 230 & $204.61 \pm 11.08$ \\
\hline \hline V-Po & 119 & 158 & $140.39 \pm 9.14$ & 118 & 160 & $135.53 \pm 9.38$ \\
\hline \hline V-N & 79 & 151 & $103.54 \pm 14.30$ & 67 & 119 & $92.57 \pm 11.95$ \\
\hline
\end{tabular}

\subsection{Data Mining and Clustering Analysis}

A clustering was performed on the complete database to find distinctions between people. The algorithm, on a large scale, detected three groups. When doing the comparison with the class gender, there is an error of $35.38 \%$ in the classification of 
Mariana Martinez-Valencia, José-Antonio Vazquez-Lopez, Carolina Hernandez-Navarro, et al.

the instances, however, the clusters reveal different characteristics of people (see Figure 3).

\subsection{Algorithms for Classification}

The algorithms tested do not differ a change of significance of 5\%. As a result, it is not possible to indicate which algorithm performs better. However, with the results provided, it is observed that the attributes are informative. This after observing that they are better than applying the baseline classifier Zero R, which, part of trivial assumptions.

Table 4. Algorithm classification.

\begin{tabular}{|c|c|c|c|c|c|c|c|c|}
\hline $\begin{array}{l}\text { Percent } \\
\text { correct }\end{array}$ & $\begin{array}{l}\text { Kappa } \\
\text { statistic }\end{array}$ & $\begin{array}{c}\text { Mean } \\
\text { absolute } \\
\text { error } \\
\end{array}$ & $\begin{array}{l}\text { RMS } \\
\text { error }\end{array}$ & $\begin{array}{c}\text { Relative } \\
\text { absolute } \\
\text { error }\end{array}$ & $\begin{array}{l}\text { Root relative } \\
\text { squared error }\end{array}$ & F measure & MCC & $\begin{array}{c}\text { Area under } \\
\text { ROC }\end{array}$ \\
\hline 0.83 & 0.66 & 0.17 & 0.38 & 0.34 & 0.76 & 0.84 & 0.67 & 0.92 \\
\hline 0.06 & 0.13 & 0.06 & 0.08 & 0.12 & 0.02 & 0.05 & 0.13 & 0.05 \\
\hline \multicolumn{9}{|c|}{$\mathrm{J} 48$} \\
\hline 0.76 & 0.51 & 0.25 & 0.47 & 0.50 & 0.95 & 0.75 & 0.52 & 0.78 \\
\hline 0.07 & 0.14 & 0.07 & 0.08 & 0.14 & 0.15 & 0.08 & 0.14 & 0.09 \\
\hline \multicolumn{9}{|c|}{ Logistic } \\
\hline 0.81 & 0.63 & 0.21 & 0.40 & 0.42 & 0.79 & 0.83 & 0.63 & 0.87 \\
\hline 0.09 & 0.17 & 0.06 & 0.09 & 0.13 & 0.17 & 0.08 & 0.17 & 0.07 \\
\hline \multicolumn{9}{|c|}{ OneR } \\
\hline 0.77 & 0.54 & 0.23 & 0.47 & 0.45 & 0.95 & 0.79 & 0.55 & 0.77 \\
\hline 0.06 & 0.12 & 0.06 & 0.06 & 0.12 & 0.12 & 0.05 & 0.12 & 0.06 \\
\hline \multicolumn{9}{|c|}{ ZeroR } \\
\hline 0.53 & 0.00 & 0.50 & 0.50 & 1.00 & 1.00 & 0.69 & $\mathrm{NaN}$ & 0.50 \\
\hline 0.01 & 0.00 & 0.00 & 0.00 & 0.00 & 0.00 & 0.01 & $\mathrm{NaN}$ & 0.00 \\
\hline \multicolumn{9}{|c|}{ IBk } \\
\hline 0.80 & 0.58 & 0.22 & 0.39 & 0.44 & 0.78 & 0.83 & 0.60 & 0.85 \\
\hline 0.05 & 0.10 & 0.04 & 0.05 & 0.08 & 0.10 & 0.04 & 0.09 & 0.05 \\
\hline \multicolumn{9}{|c|}{ PART } \\
\hline 0.74 & 0.48 & 0.26 & 0.49 & 0.53 & 0.99 & 0.74 & 0.49 & 0.76 \\
\hline 0.08 & 0.15 & 0.07 & 0.08 & 0.15 & 0.17 & 0.08 & 0.15 & 0.08 \\
\hline
\end{tabular}

\section{Discussion}

When the Data mining tools are implemented in high performance parallel processing systems, can analyze massive data bases in just a few minutes. Faster 
processing means that users can automatically experiment with more models to understand complex data [7,8]. High speed is practical for the user and makes possible to analyze immense amounts of data. The great data bases, as well, can produce better predictions. The data bases can be huge as well on depth as well as on width, for example, more columns. As a result, many times, analysts must limit the number of variables to examine when the manual analysis is done due to limitations on time. However, variables that are suppressed because they seem without importance can provide information about unknown models. Bigger samples produce fewer estimation errors and deflections and allow users to make inferences about small but important population segments.

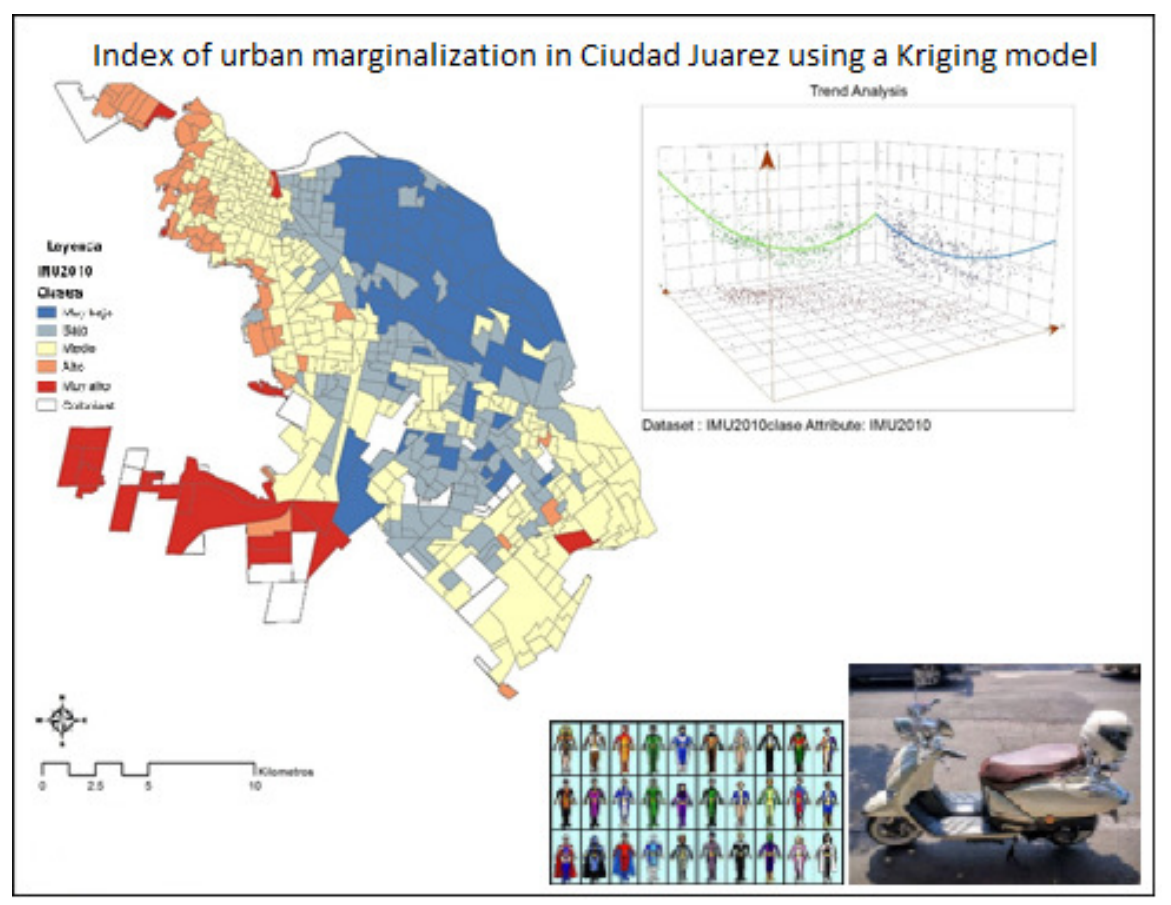

Fig. 4. Index of urban marginalization in Ciudad Juárez using Kriging model.

\section{Conclusions and Future Research}

The Data Mining tools to discover knowledge sweep the data bases and identify previously hidden models in only one step. Data mining techniques can generate benefits for the automatization of existing hardware and software platforms and can be implemented into new systems as the existing platforms get updated and new products are developed [7]. We use a Data mining tool called WEKA to analyze data.

As future research, we propose to develop a model that allows explaining the behavior showed by the environmental traffic and vial education, and how affects their activities like organize nocturnal travels together, activism, registration groups. 
Another future research and application of the data gathered here is the design and the determination of a specific helmet to Go-karts.

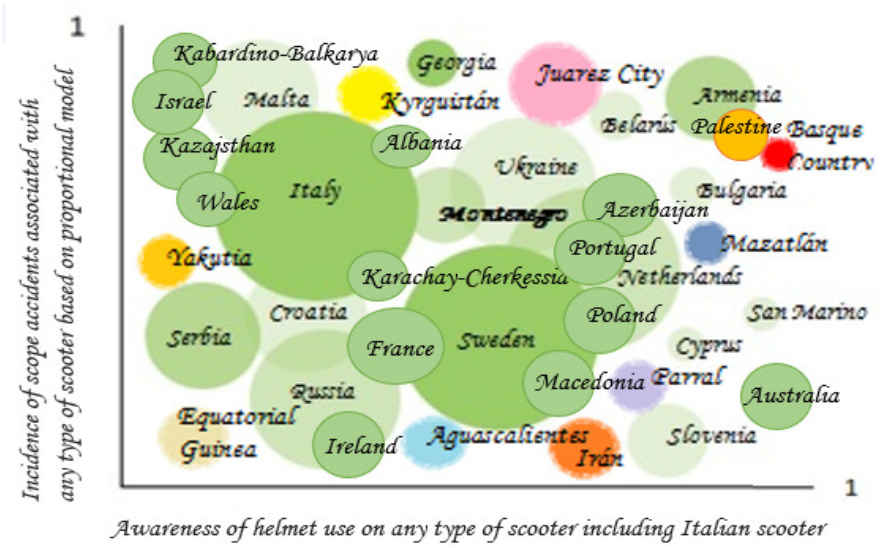

Fig. 6. Comparative of transit accidents in 39 different societies related with any kind of Motorbike including Italian Scooter: Green: European and Australian societies; Yellow and Orange: Asian societies; Brown: African Society; Blue and Purple: Mexican Societies and finally in Pink our border society of this study.

\section{References}

1. Wang, J., Thornton, J.C., Kolesnik, S., Pierson, R.N.: Anthropometry in body composition: an overview. Ann. N. Y. Acad. Sci. 904(1), 317-326 (2000)

2. Kroemer, K., Kroemer, H., Kroemer-Elbert, K.: Ergonomics: How to design for easy and efficiency. pp. 28-29 (2001)

3. Hernandez-Arellano, J.L., Talavera-Aguirre, G., Serratos-Perez, J.N., Maldonado-Macias, A.A., Garcia-Alcaraz, J.L.: Anthropometrics of University Students in Northern Mexico. Open J. Saf. Sci. Technol. 6(4), 143-155 (2016)

4. Hernandez-Arellano, J.L., Gómez-Bull, K.G.: Manual de prácticas de antropometría, biomecánica y fisiología. $1^{a}$ ed. Ciudad Juárez: Universidad Autónoma de Ciudad Juárez (2016)

5. Ward, R.E., Jamison, P.L.: Measurement precision and reliability in craniofacial anthropometry: implications and suggestions for clinical applications. J. Craniofac. Genet. Dev. Biol. 11(3), 156-164 (1991)

6. Droessler, J.: Craniometry and biological distance: biocultural continuity and change at the Late-Woodland-Mississippian interface, vol. 1. Center for Amer Archeology Press (1981)

7. Lacko, D., Huysmans, T., Vleugels, J., De Bruyne, G., Van Hulle, M.M., Sijbers, J., Verwulgen, S.: Product sizing with 3D anthropometry and k-medoids clustering. Comput. Des. 91, 60-74, (2017)

8. Probst, T., Fossati, A., Salzmann, M., Van Gool, L.: Efficient Model-free Anthropometry from Depth Data. In: 3D Vision (3DV), 2017 International Conference on, pp. 486-495 (2017)

9. Häuslschmid, R., Fritzsche, B., Butz, A.: Can a Helmet-mounted Display Make Motorcycling Safer? In: IUI, pp. 467-476 (2018) 
Determining the Optimal and Ideal Helmet for an Italian Scooter Used in a Smart City...

10. Matviienko, A., Ananthanarayan, S., Borojeni, S.S., Feld, Y., Heuten, W., Boll, S.: Augmenting bicycles and helmets with multimodal warnings for children. In: MobileHCI 15:1-15:13 (2018) 